\title{
IMPLEMENTASI E-COMMERCE BERBASIS CONTENT MANAGEMENT SYSTEM (CMS) UNTUK MENINGKATKAN HASIL PENJUALAN PADA TOKO UNA BABY
}

\author{
Sufyan Aris Saputra ${ }^{1)}$, Humisar Hasugian ${ }^{2)}$ \\ ${ }^{1}$ Sistem Informasi, Fakultas Teknologi Informasi, Universitas Budi Luhur \\ 1,2 Jl. Raya Ciledug, Petukangan Utara, Kebayoran Lama, Jakarta Selatan 12260 \\ E-mail : sufyanaris19@gmail.com ${ }^{1)}$, humisar.hasugian@budiluhur.ac.id ${ }^{2}{ }^{2}$
}

\begin{abstract}
Abstrak
Toko Una Baby merupakan salah satu badan usaha yang berfokus dalam bidang penjualan pakaian dan perlengkapan bayi. Di zaman yang sudah umumnya canggih seperti ini terutama dari sisi IT, Toko Una Baby mencoba memanfaatkan fasilitas e-commerce. Keadaan saat ini, pelanggan yang ingin membeli pakaian dan perlengkapan bayi di Toko tidak bisa melihat daftar produk yang tersedia sehingga kurang mendapatkan informasi. Pelanggan memiliki waktu yang terbatas untuk melakukan transaksi pemesanan karena hanya bisa dilakukan pada waktu jam kerja. Pada penelitian ini penulis mengimplementasikan menggunakan Content Management System (CMS) dengan metode pengembangan sistem Waterfall. Hasil penelitian menunjukkan bahwa dengan mengidentifikasi masalah yang terjadi, sistem E-Commerce mampu menyediakan beberapa fitur fungsional yang lebih memudahkan pelanggan dalam proses transaksi pembelian produk di Toko Una Baby dan dalam waktu yang lebih lama lagi. Penulis berharap dengan diciptakannya website berbasis E-Commerce ini mampu memaksimalkan pendapatan dari hasil penjualan produk dan mempromosikan nama Toko kepada pelanggan dalam jarak yang lebih luas lagi.
\end{abstract}

Kata kunci: E-Commerce, Content Management System, Pakaian dan Perlengkapan Bayi.

\section{PENDAHULUAN}

Fenomena keadaan zaman sekarang dimana kebutuhan informasi yang lebih cepat dan efisien tentunya menuntut setiap orang agar memiliki sebuah media online. Hal ini dapat dilakukan dengan penggunaan internet. Salah satunya penggunaan internet dalam bidang transaksi bisnis dikenal dengan istilah E-Commerce (Electronic Commerce) atau dapat diartikan perdagangan elektronik yaitu pembelian, penjualan, pemasaran barang dan jasa melalui internet serta jaringan komputer. Dengan menggunakan internet, proses perniagaan dapat dilakukan dengan menghemat biaya dan waktu. Toko Una Baby adalah sebuah Toko yang menjual berbagai model pakaian dan perlengkapan bayi. Dilihat dari keadaan Toko saat ini, prakteknya para pelanggan yang ingin membeli pakaian dan perlengkapan bayi supaya datang langsung ke Toko agar bisa melihat produk yang tersedia dan selanjutnya melakukan transaksi. Tentunya pelanggan hanya bisa melakukan pembelian di waktu jam kerja Toko. Dari sisi jumlah pelanggan juga dirasa belum maksimal karena area pemasaran hanya disekitar Kota dimana Toko ini berjualan. Maka dari itu, penulis mencoba untuk merancang ECommerce dengan memanfaatkan teknologi internet dalam proses penjualan sehingga dapat diakses kapan dan dimana saja oleh pelanggan.

\section{METODE PENELITIAN}

\subsection{Kerangka Kerja Penelitian}

Berikut ini merupakan langkah-langkah penelitian yang dilakukan penulis dalammemberikan solusi permasalahan.

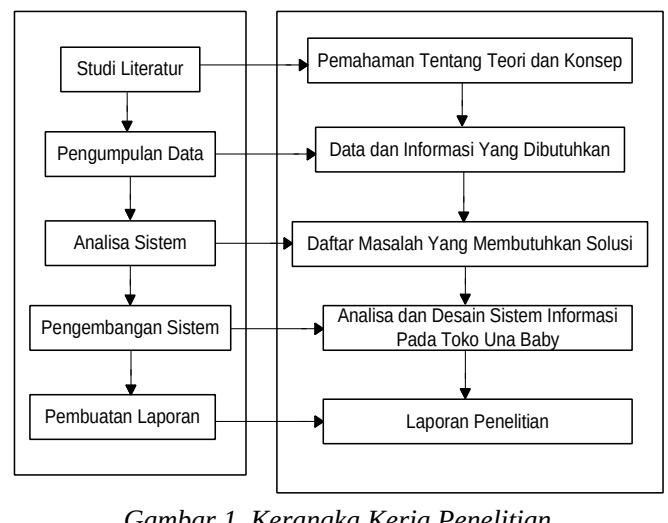

Berdasarkan kerangka kerja penelitian pada Toko Una Baby, maka dibawah ini beberapa penjelasan pada setiap langkah yaitu:

a. Studi Literatur

Pada proses ini dilakukan pencarian beberapa landasan teori yang diperoleh dari sumber buku dan juga jurnal agar bisa melengkapi landasan keilmuan yang memiliki nilai yang baik.

b. Pengumpulan Data 
Pada proses ini dilakukan proses pengumpulan data dengan metode bertemu langsung dengan pemilik Toko dan observasi untuk mendapatkan informasi terhadap proses yang sedang berjalan pada sistem penjualan di Toko Una Baby.

c. Analisis Sistem

Pada proses ini dilakukan identifikasi permasalahan pada sesuatu yang telah berjalan. Dengan demikian diharapkan penulis dapat menemukan kendala-kendala dan permasalahan yang terjadi pada sistem penjualan pada Toko Una Baby.

d. Pengembangan Sistem

Pada proses ini dilaksanakannya pengembangan sistem dengan menggunakan metode waterfall seperti gambar berikut ini :

Gambar 2. Metode Waterfall

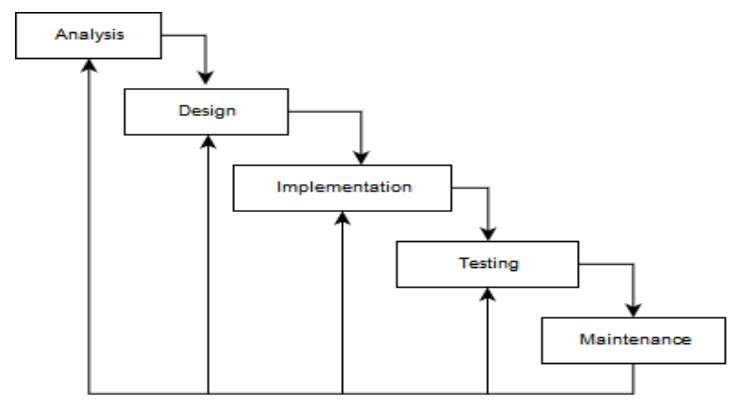

e. Pembuatan Laporan

Pada proses ini mulai dilaksanakan pembuatan beberapa laporan yang disusun berdasarkan hasil penelitian bertujuan agar mampu menghasilkan gambaran sistem yang akan dibuat.

\subsection{Metode Pengembangan Sistem}

a. Analysis

Pada tahap ini dilakukan analisis kebutuhan dari software yang akan dirancang dan dibuat, meliputi analisis beberapa fungsional atau tahapan yang dibutuhkan, analisis keluaran, analisis masukan dan analisis kebutuhan.

b. Design

Pada tahap ini dilakukan perancangan software yang diharapkan agar menghasilkan sebuah prediksi apa yang seharusnya dikerjakan oleh software dan bagaimana tampilannya meliputi rancangan output, rancangan input, rancangan struktur data yang digunakan dan rancangan struktur software. Proses ini memudahkan dalam menspesifikasikan kebutuhan dan arsitektur software secara keseluruhan.

c. Implementation

Pada tahap ini dilakukan uji coba rancangan dari tahap-tahap sebelumnya dan memulai dalam pembuatan database sesuai skema rancangan serta pembuatan software berdasarkan desain sistem.

d. Testing

Pada tahap ini dilakukan penggabungan modulmodul yang telah dibuat dan dilakukan pengujian atau testing. Proses ini dilaksanakan agar mengetahui apakah software yang dibangun sudah sesuai dengan rencana design dan apakah masih terdapat kesalahan atau tidak.

e. Maintenance

Pada tahap ini dilakukan penjagaan atau pengawasan sistem agar tetap mampu beroperasi secara benar melalui kemampuan sistem dalam mengadaptasikan diri sesuai dengan kebutuhan.

\subsection{Studi Literatur}

Berikut ini beberapa penelitian yang relevan dengan penelitian yang dilakukan sebagai studi literatur, antara lain :

a. Penulis Syahriani dengan judul "Penerapan Sistem Informasi E-Commerce Pakaian dan Perlengkapan Bayi” diterbitkan oleh STMIK Nusa Mandiri pada tahun 2017. Penelitian ini diharapkan strategi dan pemasaran akan berkembang sehingga mendorong peningkatan permintaan pasar terhadap barang [1].

b. Penulis Humisar Hasugian, Vivi Salma dengan judul "Pemodelan Sistem Informasi Pelayanan Jasa Repair Modem dan Penjualan Modul VSAT Pada PT. Paradise Communications Berbasis Object Oriented Menggunakan Unified Modelling Language" diterbitkan oleh STMIK AMIKOM Yogyakarta pada tahun 2017. Peneltian ini bertujuan kinerja staff semakin mambaik dan pelayanan terhadap customer semakin meningkat [2].

\section{HASIL DAN PEMBAHASAN}

\subsection{Business Model Canvas}

Menurut Frans Royan [3] Business Model Canvas berguna untuk menggambarkan kanvas tersebut sebagai selembar kertas bagi seorang penulis, pelukis atau layar komputer bagi seorang desainer. Business Model Canvas ini juga digunakan untuk memvisualisasikan gagasan, logika, berpikir 
atau kerangka kerja para desainer. Berikut ini adalah business model canvas pada Toko Una Baby:

Gambar 3. Business Model Canvas

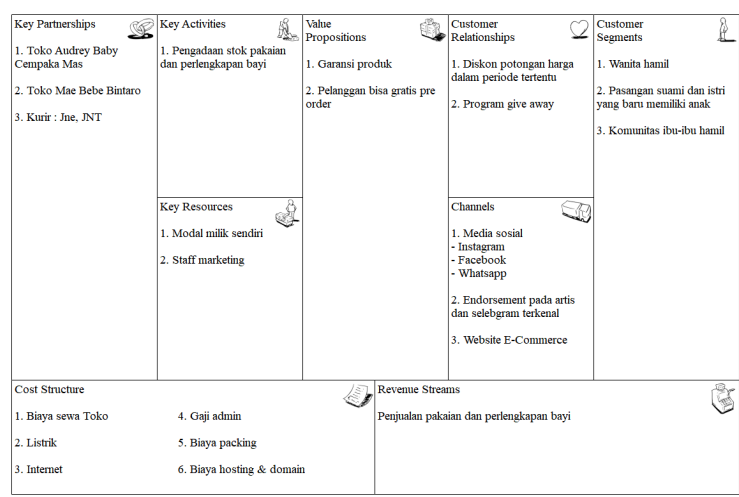

\subsection{Activity Diagram}

a. Proses Pendaftaran

Setiap pelanggan yang sudah melakukan pemesanan produk dan ingin transaksi pembayaran supaya login atau registrasi ke sistem terlebih dahulu. Kemudian sistem akan mengecek data yang telah dientry oleh pelanggan. Jika tidak sesuai, pelanggan supaya memperbaiki atau melengkapi data yang kurang valid. Jika data sudah sesuai, maka sistem akan menyimpan data tersebut dan mengirim notifikasi email registrasi kepada pelanggan.
Gambar 4. Proses Pendaftaran

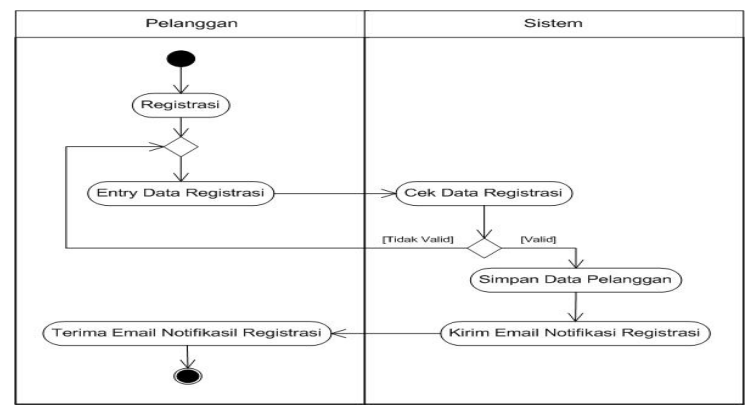

b. Proses Pemesanan

Ketika pelanggan ingin belanja, pelanggan bisa memilih beberapa produk yang diinginkan dan memasukannya ke keranjang belanja. Pelanggan juga bisa mengatur jumlah pesanan yang diinginkan. Setelah itu pelanggan memilih halaman checkout untuk melengkapi data bukti pesanan.

Gambar 5. Proses Pemesanan

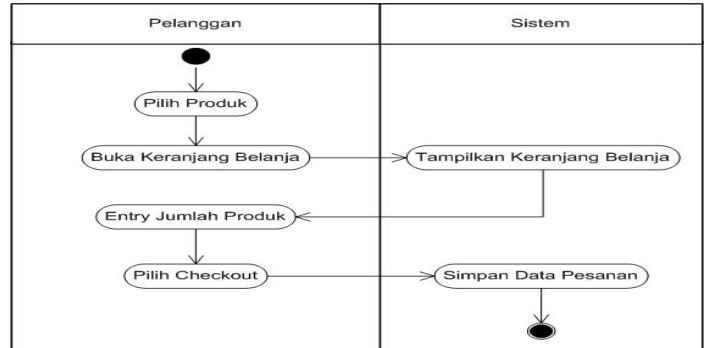

c. Proses Pembuatan Laporan

Admin akan mencetak beberapa laporan pada periode yang diinginkan. Setelah selesai, laporan tersebut akan diserahkan kepada pemilik Toko. 


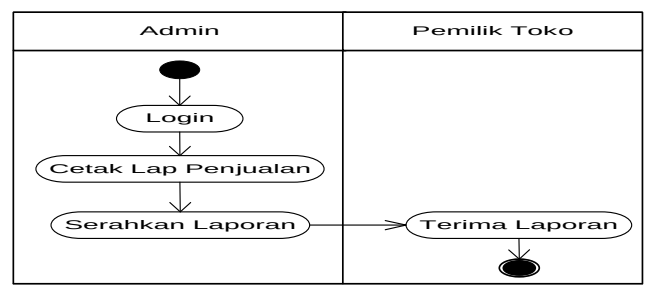

Gambar 6. Proses Cetak Laporan Penjualan

\subsection{Use Case Diagram}

Use Case Diagram merupakan diagram yang dapat digunakan untuk menggambarkan interaksi antara pengguna akhir dengan sistem. Berdasarkan proses bisnis yang telah dijelaskan sebelumnya, maka teridentifikasi beberapa kebutuhan sistem baru diantaranya sebagai berikut :

Gambar 7. Use Case Diagram Master
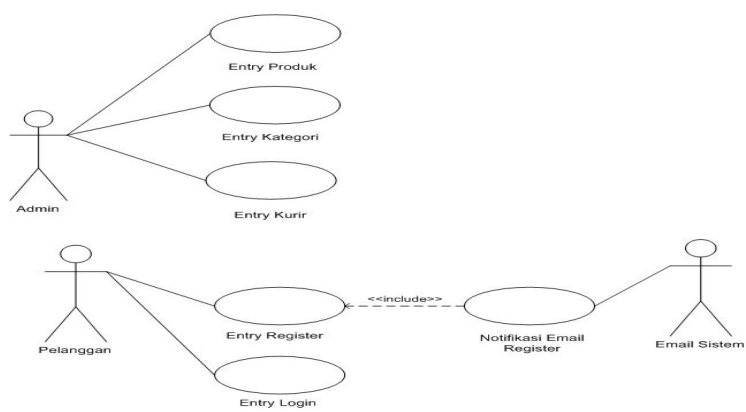

Pada gambar 7. merupakan use case diagram data master pada Toko Una Baby. Terdapat 3 data master yang khusus di entry oleh bagian admin. Sedangkan 2 master lainnya di entry oleh pihak pelanggan yang saling terhubung dengan email sistem.
Gambar 8. Use Case Diagram Transaksi
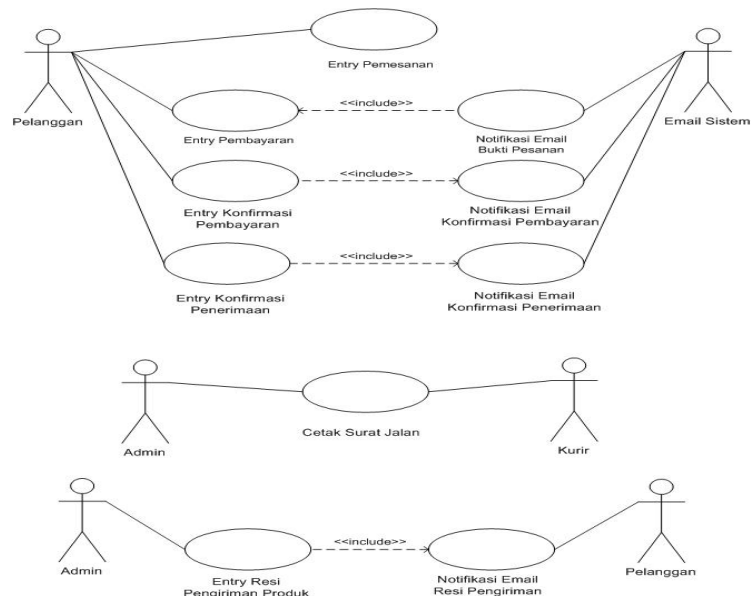

Pada gambar 8. merupakan use case diagram transaksi pada Toko Una Baby. Ketika pelanggan melakukan transaksi akan secara otomatis mendapat email dari sistem. Admin juga bisa mencetak surat jalan yang akan diletakkan pada pesanan pelanggan. 
Gambar 9. Use Case Diagram Cetak Laporan

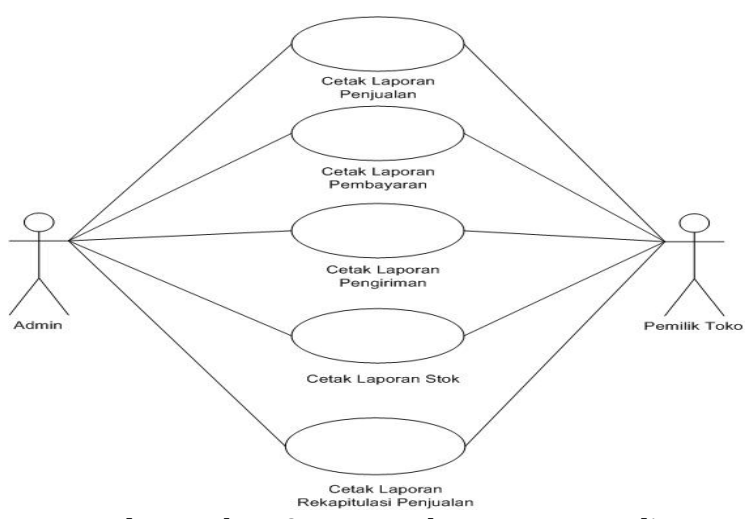

Pada gambar 9. merupakan use case diagram cetak laporan pada Toko Una Baby. Setiap bulan admin akan mencetak beberapa laporan, kemudian diserahkan kepada pemilik Toko bertujuan untuk pengambilan keputusan.

\subsection{Rancangan Layar}

Berikut ini adalah beberapa rancangan layar yang terdapat pada Toko Una Baby berbasis ECommerce :
Gambar 10. Rancangan Layar Entry Data Produk

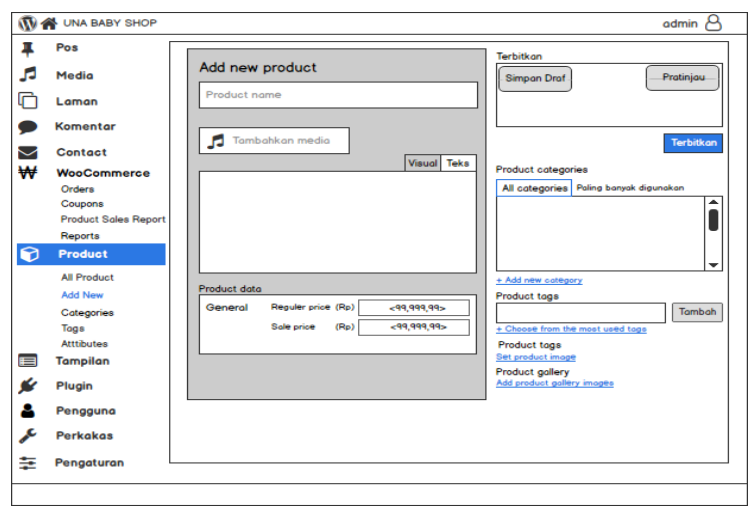

Pada gambar 10. merupakan rancangan layar untuk entry data produk baru. Terdapat field untuk mengisi data nama produk, deskripsi dan harga dari produk tersebut. Tombol pratinjau untuk melihat sementara hasil data yang telah di entry. Tombol terbitkan jika produk sudah siap untuk dipasarkan ke pelanggan. 
Gambar 11. Rancangan Layar Entry Data Kategori

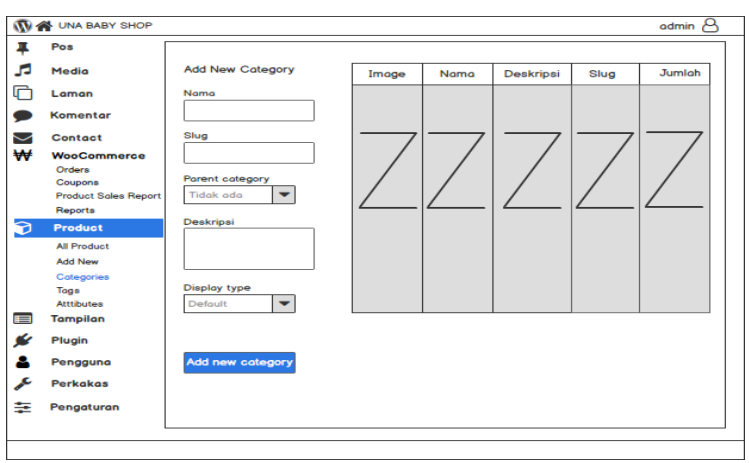

Pada gambar 11. merupakan rancangan layar entry data kategori. Terdapat field untuk mengisi data nama kategori, slug dan deskripsi. Jika data sudah diisi, simpan kategori dengan menekan tombol Add new category.

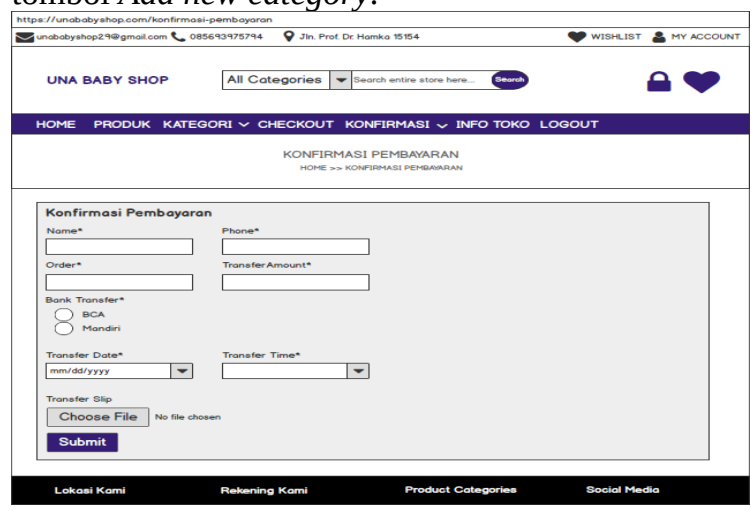

Gambar 12. Rancangan Layar Konfirmasi Pembayaran
Pada gambar 12. merupakan rancangan layar konfirmasi pembayaran pada tampilan pelanggan setelah pelanggan melakukan transfer. Terdapat field data nama pelanggan, no handphone, jenis bank, tanggal transfer dan tombol upload bukti transfer. Ketika pelanggan sudah mengisi data tersebut dengan lengkap, pelanggan menekan tombol submit untuk menyimpan data konfirmasi pembayaran.

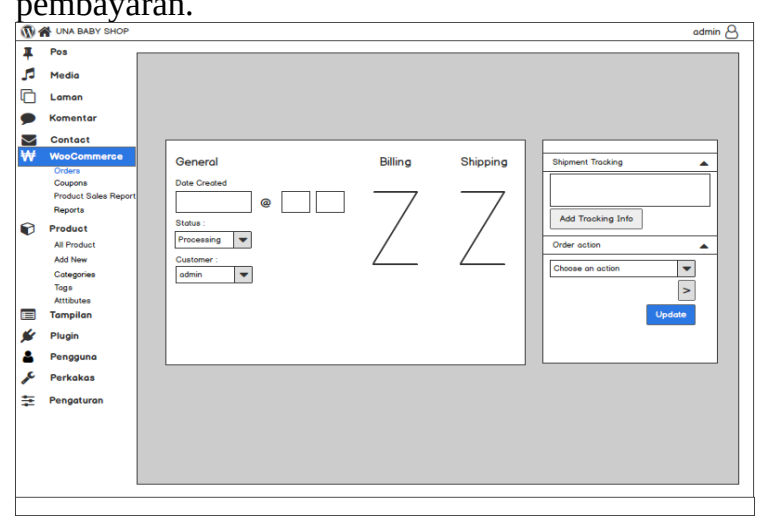

Gambar 13. Rancangan Layar Konfirmasi Pengiriman

Pada gambar 13. merupakan rancangan layar konfirmasi pengiriman. Admin akan mengubah status pesanan dan menekan add tracking info untuk mengentry nomor resi pengiriman. Tombol update bertujuan untuk menyimpan resi tersebut. 


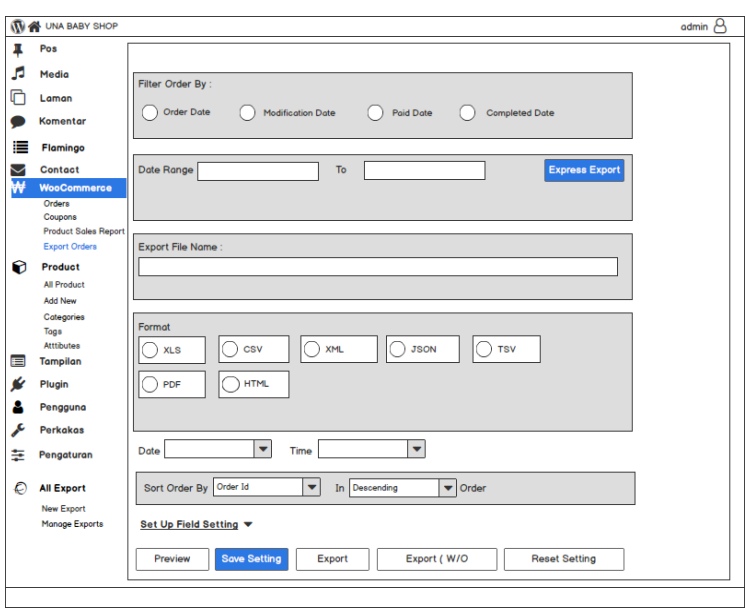

Gambar 14. Rancangan Layar Cetak Laporan Penjualan

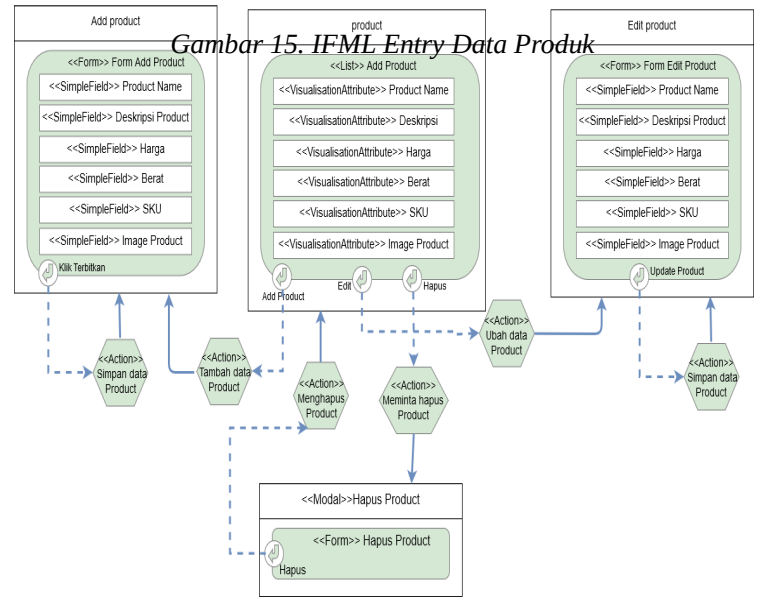

Pada gambar 14. merupakan rancangan layar cetak laporan penjualan. Terdapat beberapa pilihan menu periode dan jenis format laporan yang diinginkan. Tombol preview untuk melihat hasil cetakan sementara laporan. Serta tombol express export jika ingin mencetak laporan penjualan tersebut.

\subsection{Interaction Flow Modeling Language (IFML)}

Menurut Suryanto, Pattiasina dan Soetarmono [4] IFML (Interaction Flow Modeling Language) merupakan jenis bahasa pemodelan yang memiliki kemiripan dengan WebML dan juga mewakili generalisasi dari domain web untuk aplikasi generic pemodelan front-end. Berikut ini contoh IFML pada Toko Una Baby seperti gambar dibawah ini :

Pada gambar 15. merupakan IFML entry data produk baru. Admin mengisi beberapa data produk ke dalam field add new product diantaranya seperti nama produk, deskripsi, harga, berat, sku dan gambar produk. Jika admin sudah pernah mengisi data produk maka akan tampil beberapa list produk. Tombol edit tersedia untuk mengubah data produk yang sudah pernah di entry. Setelah admin mengedit data produk, admin menyimpan perubahan tersebut ke dalam sistem dengan menekan tombol simpan. Tombol hapus digunakan untuk menghapus data produk. Sedangkan tombol terbitkan berfungsi untuk menampilkan produk kepada pelanggan.

\subsection{Strategi Search Engine Optimization (SEO)}

Menurut Su Rahman [5] SEO memiliki pengertian yaitu serangkain teknik yang dilakukan agar website dapat dengan mudah ditemukan oleh google. Dibawah ini adalah hasil dari penerapan teknik SEO yang dicoba pada Toko Una Baby : 
Gambar 16. Hasil SEO

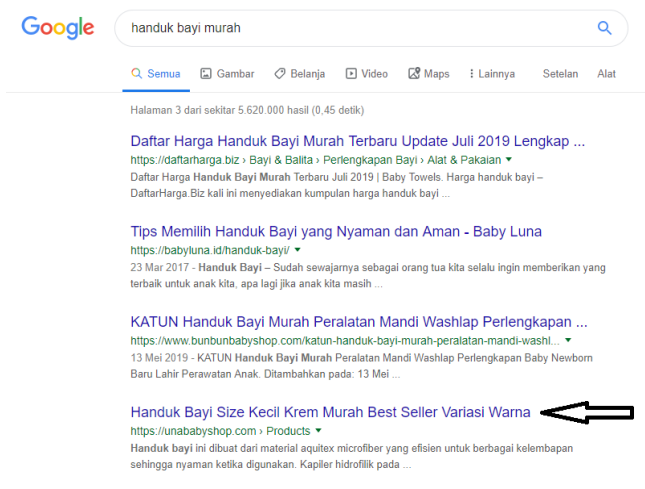

\section{KESIMPULAN}

Setelah mempelajari permasalahan yang terjadi pada Toko Una Baby dan juga solusi pemecahan yang diberikan, maka dapat diambil beberapa kesimpulan yang dapat dirinci sebagai berikut :

a. Dengan adanya fitur daftar produk yang dijual di Toko, saat ini pelanggan dimudahkan untuk mendapatkan informasi produk yang ingin dicari atau dibutuhkan.

b. Dengan dibuatnya E-Commerce pada Toko Una Baby, maka membuat pelanggan tetap bisa berbelanja meskipun jam kerja Toko telah tutup.

c. Dengan menggunakan teknik SEO (Search Engine Optimization), maka memudahkan pelanggan untuk melakukan pencarian nama domain Toko.

d. Dengan adanya fitur kategori produk, maka saat ini admin dimudahkan untuk mengelola produk sesuai dengan kategorinya.

\section{DAFTAR PUSTAKA}

[1] Syahriani., 2017, Penerapan Sistem Informasi ECommerce Pakaian dan Perlengkapan Bayi. Jakarta, STMIK Nusa Mandiri, pp77-82.

[2] Hasugian, H., Salma, V., 2017, Pemodelan Sistem Informasi Pelayanan Jasa Repair Modem dan Penjualan Modul VSAT Pada PT. Paradise Communications Berbasis Object Oriented
Menggunakan Unified Modeling Language. Prosiding Seminar Nasional Teknologi Informasi dan Multimedia 2017, pp49-55.

[3] Royan, Frans, 2015, Bisnis Model Kanvas Distributor Mematenkan Kinerja Optimal Distributor dan 30 Kesalahan Yang Dilakukan, Jakarta, Gramedia Pustaka Utama, p12.

[4] Suryanto, S.P., Pattiasina, T.J., Soetarmono, Anggya, 2017, Perancangan dan Pengembangan Toko Online Dengan Metode Interaction Flow Modelling Language, 6(1), p8.

[5] Rahman, S, 2018, Cara Mudah Menghasilkan Website Terbaik Untuk Usaha Online, Jakarta, PT Elex Media Komputindo, p12. 